\title{
Response Characteristics of Internal Wave to Wind Stress in a Shallow Closed Water Body
}

\author{
Hamagami, Kunihiko \\ Laboratory of Water Resources Engineering, Division of Rural Engineering, Department of \\ Bioresource, Faculty of Agriculture, Ehime University
}

Mori, Ken

Laboratory of Bioproduction and Environment Information Sciences, Division of Bioproduction and Environment Information Sciences, Department of Bioproduction and Environmental Science, Factory of Agriculture, Kyusyu University

\section{Iguchi, Shota}

Laboratory of Bioproduction and Environment Information Sciences, Division of Bioproduction and Environment Information Sciences, Department of Bioproduction and Environmental Science, Factory of Agriculture, Kyusyu University

\section{Hirai, Yasumaru}

Laboratory of Bioproduction and Environment Information Sciences, Division of Bioproduction and Environment Information Sciences, Department of Bioproduction and Environmental Science, Factory of Agriculture, Kyusyu University

https://doi.org/10.5109/19540

出版情報: 九州大学大学院農学研究院紀要. 56 (1)，pp.123-128，2011-02. Faculty of Agriculture， Kyushu University

バージョン :

権利関係 : 


\title{
Response Characteristics of Internal Wave to Wind Stress in a Shallow Closed Water Body
}

\author{
Kunihiko HAMAGAMI ${ }^{1}$, Ken MORI*, Shota IGUCHI \\ and Yasumaru HIRAI
}

\author{
Laboratory of Bioproduction and Environment Information Sciences, Division of Bioproduction and \\ Environment Information Sciences, Department of Bioproduction and Environmental Science, \\ Factory of Agriculture, Kyusyu University, Fukuoka 812-8581, Japan \\ (Received October 29, 2010 and accepted November 8, 2010)
}

\begin{abstract}
This study was conducted in a shallow reservoir for agriculture to examine the response characteristics of the internal seiche to wind action in a closed water body. A observational results revealed that the frequency characteristics of the wave of density interface change with time corresponding to the unsteady wind action, and that the time delay of internal seiche which corresponds to the wind stress is about almost 25 minutes in Shikinawa Lake. When the Wedderburn number is between $10^{\circ}$ to $10^{2}$, the cycle of the wave in the density interface is almost same as the internal seiche. Moreovr, the value of the Wedderburn number to cause the internal vibration is about $10^{2}$ in Shikinawa Lake.
\end{abstract}

\section{INTRODUCTION}

In closed water bodies where there is no disturbance and with little inflow and outflow, self-purification is insufficient and eutrophication or water pollution is more likely to happen. Recently, concern about environmental problems is increasing and closed water bodies with serious eutrophication had been studied in various fields of research. One of the primary characteristics of a water body that controls water quality is the potential for mixing. Mixing is important in maintaining, distributing and improving water quality in all water bodies. In closed water bodies, external or internal mixing forces depend on its geometrical properties and boundary types.

An important factor influencing water quality in relatively still, deep waters, such as lakes and reservoirs, is stratification. Stratification occurs when the water in a lake or reservoir acts as two different bodies with different densities. It is commonly caused by temperature differences, leading to differences in density, and occasionally by differences in solute concentrations. Water quality in bodies of water is also subject to many influences. It is common for the lower layer to have a significantly lesser oxygen concentration compared to the upper layer. When anoxic conditions occur in bottom sediments, various compounds may increase in interstitial waters and diffuse from the sediments into the lower water layer. Substances produced in this process include ammonia, nitrate, phosphate, sulfide, silicate, iron, and manganese compounds.

Wind is the major external input responsible for mixing in closed water bodies, e.g. lake. Wind adds kinetic energy and affects the lake through the shear it imparts on the water surface (Mori et al., 1989; Ookubo and

${ }^{1}$ Laboratory of Water Resources Engineering, Division of Rural Engineering, Department of Bioresource, Faculty of Agriculture, Ehime University, JSPS Research Fellow

* Corresponding author (E-mail: moriken@bpes.kyushu-u.ac.jp)
Muramoto, 1988). This shear drags the water in the downwind direction, adding kinetic energy and causing surface currents, surface waves, and a surface set up. This set up results in a basin-scale circulation: bottomwater return currents compliment the surface-water motion. Although the surface set up may only be a few millimeters or centimeters, this result in a much greater tilting of the density interface. Thus, the potential energy of the lake tips downward. When the wind stops, this potential energy of the lake is released, causing basin-scale waves called seiches, and other internal waves develop which also result in boundary currents and boundary mixing (Michioku et al., 1999).

In a small and shallow lake, hydraulic conditions are considered as a major force that impacts strongly mixed state and water quality. Shallow water depths and strong water flow can help the lake to be mixed well. A theoretical research on internal seiche has been performed by many researchers (Ootani et al., 1988; Sato, 2000). Although these studies reported on the characteristics of wind-induced flow and upwelling flow by hydraulic experiment and numerical analysis, the observations to examine the its validity is not enough. Thus, this study conducted field observation in a shallow reservoir for agriculture to examine the response characteristics of the internal seiche to wind action in a closed water body. The chosen study site is the Shikinawa Lake in Fukuoka Prefecture, Japan. Shikinawa Lake is a small, shallow, and stratified lake and is a good example of a closed water body.

\section{METHODS AND RESULTS}

\section{Observational methods}

The properties of Shikinawa Lake

The Shikinawa Lake is located in Kasuyamachi, a city in the west area of Fukuoka Prefecture, Japan (Fig. 1) and its water is used for agricultural irrigation. During the observation period, there were no inflow, outflow and precipitation, making the lake a temporally 


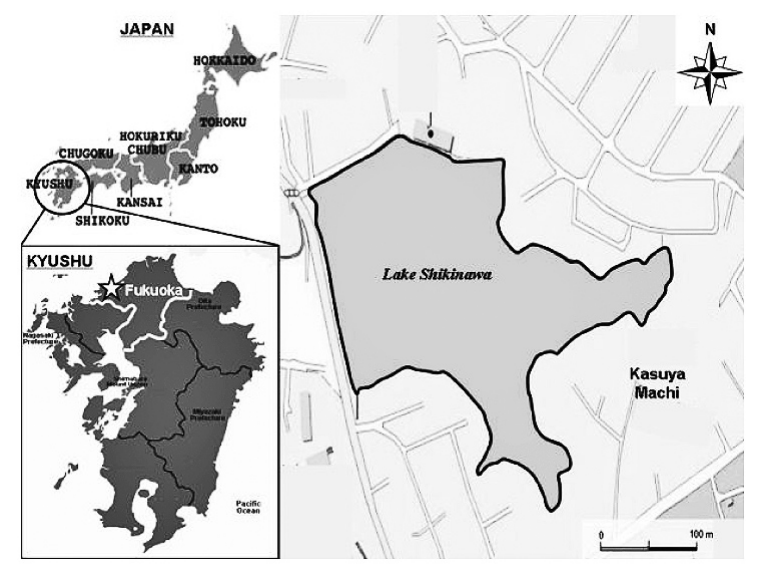

Fig. 1. Location of the Shikinawa Lake.

closed water body. Depending on climate condition, hydraulic properties of the lake vary during the field observation. In addition, the water chestnuts (Eleocharis dulcis) were growing on about one-third of the water surface.

Data collection for the Shikinawa Lake

Field observation was performed during $1^{\text {st }}$ to $5^{\text {th }}$ May 2008 to determine the water quality characteristics of the lake at the end of spring season. To investigate water quality, three stations, namely St.1, St.2, and St.3, were set along the longest west-east line of the lake with St.1 at the west side, St.3 at the east side and St.2 at the center of the lake (Fig. 2). Distances were set equal to $75 \mathrm{~m}$ between stations St.1 and St.2, and $125 \mathrm{~m}$ between St.2 and St.3. The depth of lake at station St.1 is $2.65 \mathrm{~m}$, 2.63 at St.2, and 2.25 at St.3. Water quality parameters including water temperature, dissolved oxygen concentration, total nitrogen, total phosphorus, nitrite and nitrate ions were measured. Water temperature was measured using a vertical sensor system at $0.2 \mathrm{~m}$ intervals from the water surface downward. Data were recorded automatically every two minutes using thermodac recorders.

A meteorological measuring system was set at the center of the lake. Wind speed, air temperature, and relative humidity were measured at the heights of $1.5 \mathrm{~m}$ and $0.5 \mathrm{~m}$ above the water surface every two minutes.

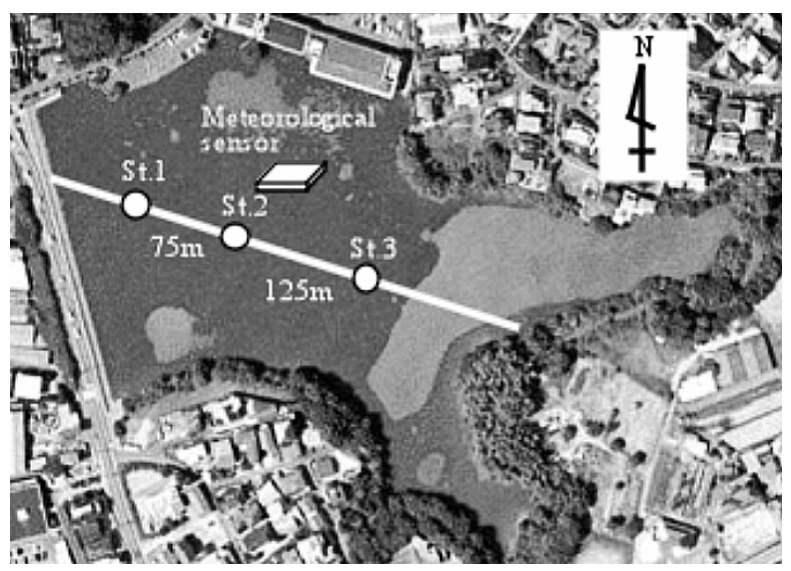

Fig. 2. Lay-out of the measurement stations.
For clockwise change of wind direction from 0 degree to 360 degree, 0 degree was set correspondingly to the main wind direction from St.1 to St.3. A couple of sensors were set at about $0.15 \mathrm{~m}$ above the water surface to measure the incoming solar radiation and reflection from the water surface, with measurement time interval of also two minutes.

\section{Observational results and discussions}

Daily patterns of meteorological factors and water temperature

Time series of observed meteorological factors and water temperature at each water depth are shown in Fig. 3. The observed result on solar radiation shows clear weather throughout the observation period, except on $1^{\text {st }}$ May. The air temperature reflected the effect of solar radiation, which was high during daytime but very low during nighttime; and higher solar radiation took less time to rise up the air temperature. At the time of observation, wind speed was about $3 \mathrm{~m} / \mathrm{s}$ at daytime and weak at nighttime, that is, the thermal disturbance was more significant during the time of observation.

At daytime, the water temperature at the upper layer increases due to the solar radiation, then, it decreases at nighttime due to radioactive cooling. At the lower layer, water temperature was hardly changed by the thermal disturbance, but it fluctuated slightly when the wind blew. In $1^{\text {st }}$ May, water temperature changed slowly through the day. The difference between the highest and lowest temperature of all water layers were small due to low amount of incoming solar radiation - the main source of heating process. The mixing component dominated throughout the day, as there was no difference of temperature in layers shallower than $1.23 \mathrm{~m}$. As it

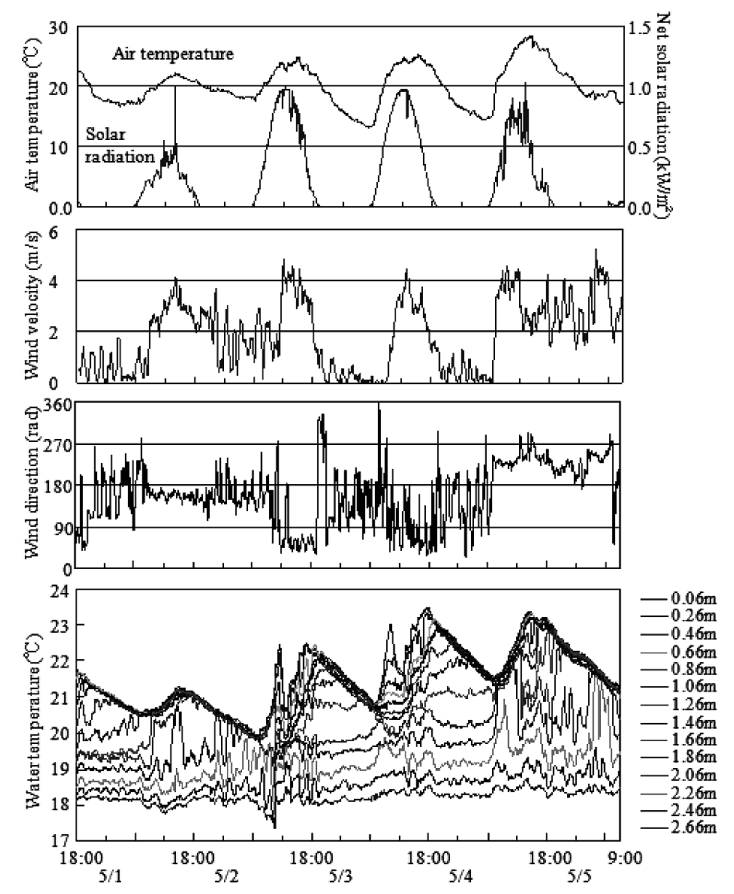

Fig. 3. Time series of observed meteorological factors and water temperature. 
meant, wind action was stronger and more significant than the effect of stratification process generated by solar heating on that day. In $2^{\text {nd }}$ May, water temperatures measured at all depths were much different than that of the previous day: both in value and in time of occurrence. This is caused by higher solar radiation and larger variation in amplitude and direction of the wind.

Nevertheless, the thermal stratification formed during daytime didn't quite disappear at nighttime. Thus, it can be surmised from above data that the lower layer of Shikinawa Lake had been in low-oxygen state due to the strong thermal stratification during the preceding spring season. This occurrence brought damage to the aquatic organisms and had adverse impact on farm irrigation. Although the water temperature variation in the lower layer had hardly responded to the thermal disturbance, it changed in some hourly periods due to the development of wind. It is thought that the cycle of change showed the internal wave based on the wind stress. The internal wave plays a big role in the vertical mixing of water in the stratified water body.

Characteristics of the internal wave

The internal wave component was determined from the time series data of water temperature by the procedure, as subsequently discussed. Since the distribution of water temperature was almost straight-line at the depth lower than the thermocline, the depth of predefined temperature was calculated by interpolating the data from each sensor. Fig. 4 shows the time change of internal wave and the friction speed in axial direction during nighttime from 11p.m. $3^{\text {rd }}$ May to 9a.m. $5^{\text {th }}$ May, at each station. The predefined temperature, $20.6{ }^{\circ} \mathrm{C}$, was the value at the density interface. This figure indicates that the vibration amplitude of the density interface increases as the wind develops. The maximum wave height was about $30 \mathrm{~cm}$, corresponding to $3 \mathrm{~m} / \mathrm{s}$ wind speed which is the average value during the time of observation. The wave height at St.2 is smaller compared to the wave height at St.1 and St.3; while the rela- tion between St.1 and St.3 was opposite phase. From the above results, it is indicated that the change of density interface represented the cycle of internal seiche.

\section{The characteristics of internal seiche}

The variation of internal wave was examined by power spectrum, autocorrelation function and cross spectrum to determine the characteristics of internal seiche. Figs. 5 and 6 show the distribution of power spectrum and the autocorrelation function of the variation of internal wave in each station to figure out the cycle and amplitude of vibration of internal seiche. These figures include 1,024 data, 2,048 minutes of observation time, from 11p.m. $3^{\text {rd }}$ May to 9a.m. $5^{\text {th }}$ May. Fig. 5 shows that the power spectrum of the variation of internal wave reached its peak at the band frequency of 1.9 hours cycle at St.1 and St.3. This is perceived to show the cycle of internal seiche. From Fig. 6, it is shown that the variation of internal wave at St.2 was not exactly periodic despite a marked periodicity at St.1 and St.3. In addition, Fig. 6 also shows that the time lag between St.1 and St. 3 was about 2 hours, that is, the dominant cycle of the internal seiche was about 2 hours. Assumed to be in a closed rectangular water body, the cycle of the internal seiche, $T_{i}$, is expressed as,

$$
T_{i}=\frac{2 l}{\sqrt{\frac{\left(1-\rho_{1} / \rho_{2}\right) g h_{1} h_{2}}{\rho_{1} h}}}
$$

where $l$ is the length of lake; $\rho_{1}$ and $\rho_{2}$ are the water density in the upper and lower layers, respectively; $h_{1}$ and $h_{2}$ are the water depth of the upper and lower layers, respectively; $h$ is the total water depth; $g$ is the acceleration due to gravity. Applying the expression to Shikinawa Lake, it results to $T_{i}=2.0 \mathrm{~h}$. This value generally corresponds to the observation result.

As mentioned above, it is understood that the change

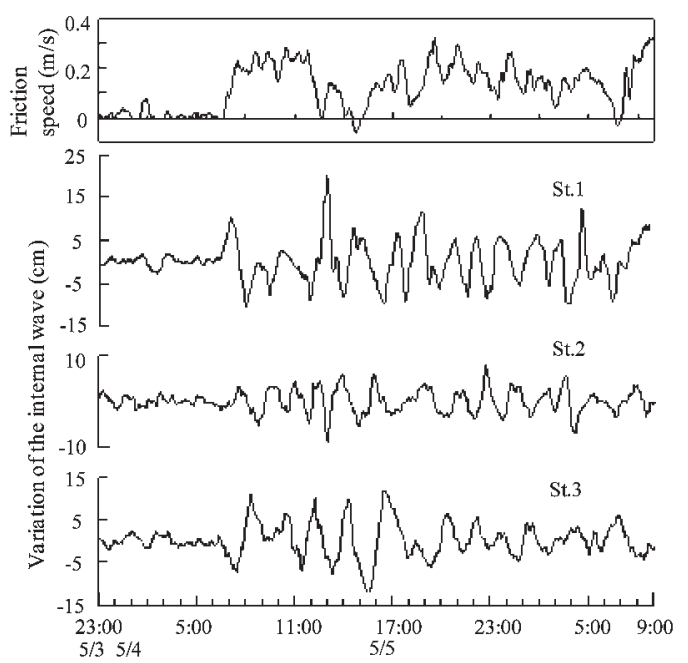

Fig. 4. The time change of internal wave and the friction speed in axial direction.

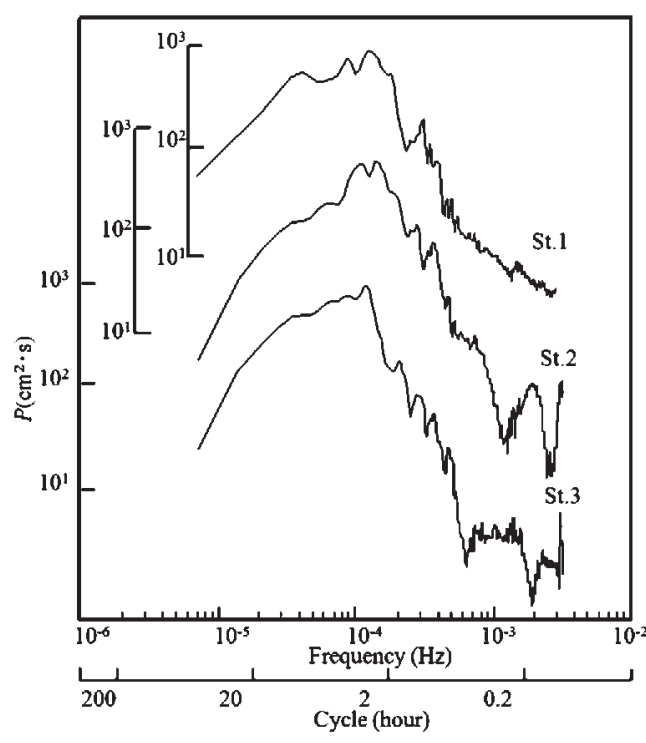

Fig. 5. The power spectrum of the internal wave. 


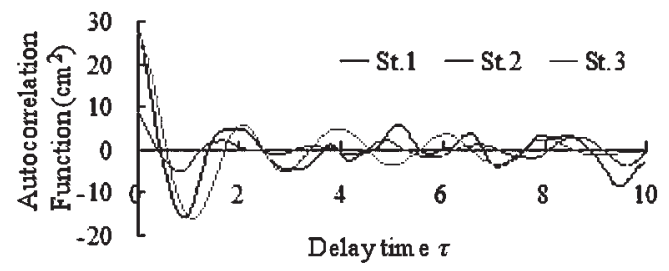

Fig. 6. The autocorrelation function of the internal wave.

of the density interface was shown as the internal wave motion by the action of the wind stress. Then, a crossspectral analysis was conducted to examine the interrelation of the wind and the change of density interface.

Fig. 7 shows the coherence and phase of the friction speed in axial direction; and the change of the density interface at each station from 11p.m. $3^{\text {rd }}$ May to 9a.m. $5^{\text {th }}$ May. The coherence and phase are defined as follows.

$$
\begin{aligned}
& \operatorname{coh}^{2}(\omega)=\frac{\left|S_{x y}(\omega)\right|^{2}}{S_{x x}(\omega) S_{y y}(\omega)}=\frac{K_{x y}{ }^{2}(\omega)+Q_{x y}{ }^{2}(\omega)}{S_{x x}(\omega) S_{y y}(\omega)} \\
& \theta_{x y}(\omega)=\tan ^{-1}\left(\frac{Q_{x y}(\omega)}{K_{x y}(\omega)}\right)
\end{aligned}
$$

where $\operatorname{coh}(\omega)$ is the square root of coherence and is a cross correlation coefficient of the Fourier frequency element of two signals; $S_{x y}(\omega)$ and $S_{y y}(\omega)$ are the spectral of time variations $x(t)$ and $y(t) ; K_{x y}(\omega)$ and $Q_{x y}(\omega)$ are the coincident spectral and the quadrature spectral; and phase $\theta_{x y}(\omega)$ shows the phase angle of $X(\omega)$ and $Y(\omega)$ which are $\omega$ direction of $x$ and $y$. The time delay, $\tau$, between two variations is shown as,

$$
\tau=\frac{\theta_{x y}(\omega)}{\omega}
$$

From Fig. 7, the peak is seen in the frequency band which is roughly equivalent to 1.7 hours cycle at each station for coherence. In addition, it is understood that internal seiche is closely related to the action of the wind because the correlation is also high in 2.0 hours which are the cycle of internal seiche in Shikinawa Lake. The

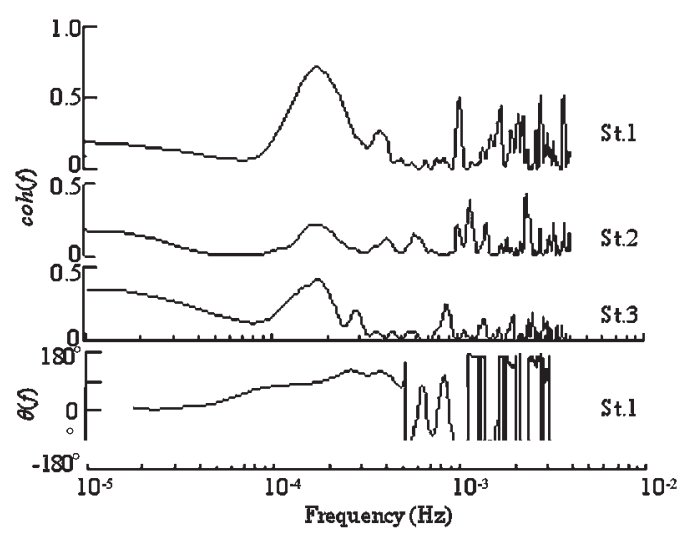

Fig. 7. The coherence and the phase between the friction speed in axial direction and the internal wave. phase in St.1 which obtained the especially high coherence value is $90^{\circ}$. As a result, it is revealed that the internal seiche responded to the wind action 25 minutes later.

Fig. 8 shows the relation of the time delay to the frequency band, showing a high coherence value from the cross spectrum of the friction speed in axis direction and the variation of density interface at St.1 and St.3 at each observation. This figure shows that the time delay in the low frequency band are similar; and, in Shikinawa Lake, the time delay of internal seiche which corresponds to the wind stress is about 25 minutes.

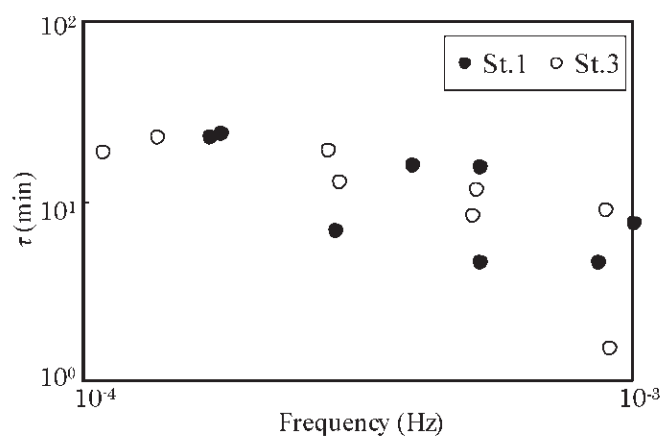

Fig. 8. The relation of time delay to the frequency band.

Wind stress and the wave height and cycle of internal seiche

The wave height change of the density interface greatly affects the fluid exchange between upper and lower layers in the density-stratified water body. Thus, the wave height and cycle of internal seiche to wind stress was examined. The wave height and cycle was calculated from various data of the density interface from 11p.m. $3^{\text {rd }}$ May to 9a.m. $5^{\text {th }}$ May, when the wind was significant and the internal seiche was sharply-defined using zero-up crossing method. Fig. 9 shows the relation between the wave height and cycle of internal seiche and the dimensionless number We (Wedderburn number) which shows the effect of the wind. We is defined as,

$$
W e=\frac{\left(\rho_{2}-\rho_{1}\right) g}{\rho_{1}} \frac{h}{u_{*}} \frac{h}{l}
$$

where $u_{*}$ is the friction speed of wind. The $u_{*}$ value used in this study is the averaged value of the friction speed during the occurrence of one wave. Moreover, the wave height and cycle of internal seiche are shown as dimensionless values, using the average water depth $h$ and the cycle of internal seiche $T_{i}$. Fig. 9 shows that the wave height and cycle of density interface decreases as the value of $W e$ increases, that is, when wind stress becomes small. Moreover, the observed results of We range from $10^{\circ}$ to $10^{2}$; and the wave cycles are distributed in about $10^{\circ}$. Therefore, it is thought that internal seiche dominantly affect the behavior of density interface in Shikinawa Lake. It was also found out that the values of 
We to cause the internal vibration is about $10^{2}$, based on the values of $W e 25$ minutes before the internal vibration occurred.
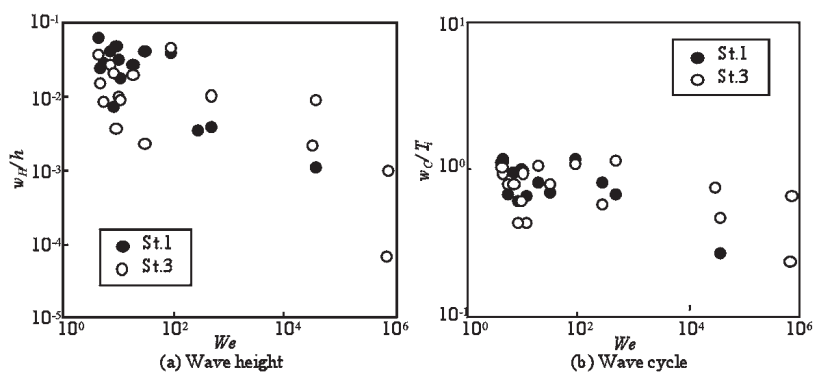

Fig. 9. The relation of Wedderburn number to the wave height and cycle of internal seiche.

\section{Application of internal seiche to a prediction model}

The observed results were applied to the prediction model proposed by Furumoto et al. (1991), about internal seiche caused by unsteady wind stress, in order to examine the adaptability of the data to a prediction model. Fig. 10 shows the vertical two-dimension stratification field, with $x$ axis as the flow direction and the $y$ axis as upward vertical direction. With the upper and lower layer shown by subscript 1 and 2, respectively, governing equations are given as follows:

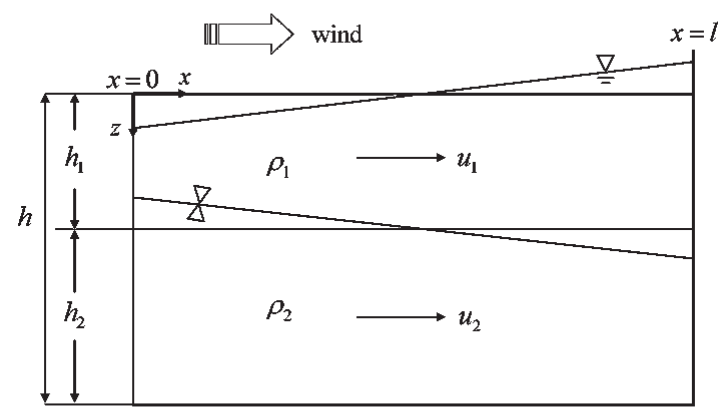

Fig. 10. The vertical two-dimensional stratification field.

upper layer

$$
h_{1} \frac{\partial u_{1 m}}{\partial x}+\frac{\partial \zeta_{1}}{\partial t}-\frac{\partial \zeta_{2}}{\partial t}=0
$$

$$
\begin{aligned}
& h_{1} \frac{\partial u_{1 m}}{\partial t}=-g h_{1} \frac{\partial \zeta_{1}}{\partial x}+\frac{1}{\rho_{1}}\left(\tau_{s}-\tau_{i}\right) \\
& h_{2} \frac{\partial u_{2 m}}{\partial x}+\frac{\partial \zeta_{2}}{\partial t}=0
\end{aligned}
$$

lower layer :

$$
\begin{aligned}
h_{2} \frac{\partial u_{2 m}}{\partial t}= & -g h_{2}\left(1-\frac{\rho_{1}}{\rho_{2}}\right) \frac{\partial \zeta_{2}}{\partial x} \\
& -g h_{2} \frac{\rho_{1}}{\rho_{2}} \frac{\partial \zeta_{1}}{\partial x}+\frac{1}{\rho_{2}}\left(\tau_{i}-\tau_{b}\right)
\end{aligned}
$$

where, $u_{1 m}$ and $u_{2 m}$ are cross-sectional average flow velocities in upper and lower layers, respectively; $\zeta_{1}$ and $\zeta_{2}$ are the displacemenst, from resting position, of the water surface and the density interface, respectively; and $\tau_{s}$, $\tau_{i}$ and $\tau_{b}$ are shear stresses at the water surface, the density interface and the bottom of water body respectively. When a constant wind acts suddenly from $t=0$, the internal seiche is shown as,

$$
\zeta_{2}=\sum_{n=1}^{\infty} Z_{2}(n, t) \cos \left(\frac{n \pi x}{l}\right)
$$

where, $Z_{2}$ is the function of the depth of desity interface (Furumoto et al., 1991). If a continuous change in wind stress is assumed, the continuous of wave pulse, the expression of internal seiche to unsteady wind stress is obtained by numerical integral as follows:

$$
\begin{aligned}
\zeta & =\int_{0}^{t}-A(\tau) \frac{\partial Z(t-\tau)}{\partial \tau} d \tau \\
& =[-A(\tau) Z(t-\tau)]_{0}^{t}+\int_{0}^{t} \frac{\partial A}{\partial t} Z(t-\tau) d \tau \\
& =A_{1} Z(t)+\left(A_{2}-A_{1}\right) Z\left(t-\tau_{1}\right)+\left(A_{3}-A_{2}\right) Z\left(t-\tau_{2}\right)+\cdots
\end{aligned}
$$

where, $A$ is the coefficient which represents the amplitude of the wave (See Furumoto et al., 1991 for the details).

The calculated results from 11p.m. $3^{\text {rd }}$ May to 9a.m. $5^{\text {th }}$ May, using the observed data as applied to the prediction model, are shown in Fig. 11. Although the calculated results roughly conform to the wave cycle of the density interface, it tends to be underestimated at time zones with large amplitude. So, it is thought that the wind stress in this prediction model was assumed to act as rectangular distribution, and the wind stress had actually acted in three dimensions. And despite the simplicity of the model, it could roughly duplicate the behavior of internal seiche. With this, it can be said that this model is effective to describe and comprehend the characteristics of density interface in a stratified water body.

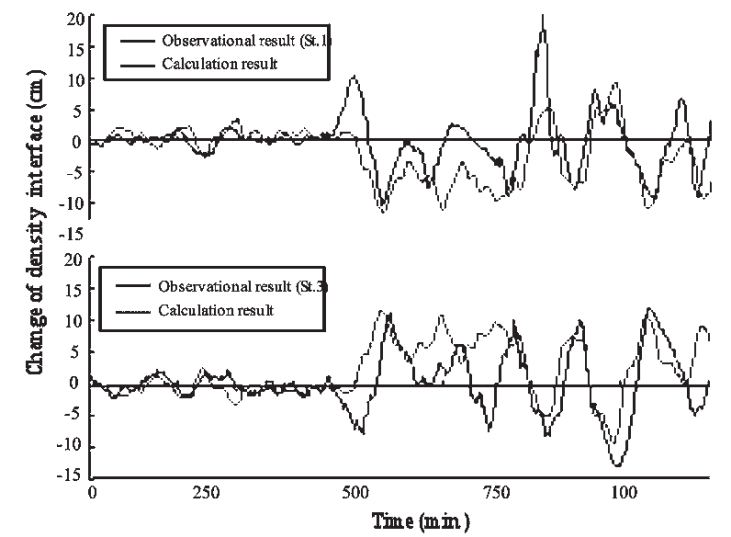

Fig. 11. The time change of density interface at St.1 and St.3.

\section{CONCLUSION}

This study was conducted in a shallow reservoir for agriculture to examine the response characteristics of 
the internal seiche to wind action in a closed water body. In Shikinawa Lake, a small, shallow and stratified lake and a good representation of a closed water body, the following results were obtained:

(1) The frequency characteristics of the wave of density interface change with time corresponding to the unsteady wind action.

(2) The time delay of internal seiche which corresponds to the wind stress is about 25 minutes.

(3) When the Wedderburn number is between $10^{\circ}$ to $10^{2}$, the cycle of the wave in the density interface is almost same as the internal seiche.

(4) The value of the Wedderburn number to cause the internal vibration is about $10^{2}$.

\section{REFERENCES}

Furumoto, K., T. Takemasa and H. Kokoda 1991 Internal seiche response of density stratified closed water domain against wind (in Japanese). Annual Journal of Coastal Engineering JSCE, 32: 722-726

Michioku, Y., T. Kanda and K. Ishikawa 1999 Sampling of Internal Waves and Natural Convection in a Reservoir Based on Water Temperature Measurements (in Japanese). Annual Journal of Hydraulic Engineering, JSCE, 43: 1049-1054

Mori K., Y. Tohara, S. Shikasyo. K. Hiramatsu. O. Kato and H. Cho 1989 The Diurnal Mixed Layer and Its Influence on the Velocity Field (at Lake Kasumigaura). Trans. of JSIDRE 144: $75-84$

Nezu I., M. Sanjou and K. Goto 2005 3-D Structure of Coherent Horizontal Vortices in Compound Open-Channel Flow with Deep Floodplain depth. Proceedings of JSCE, 789: 27-36

Ookubo K., Y. Muramoto 1988 Wind Driven Currents and Eddy Viscosity in a Shallow Lake. Proceedings of the Japan Society of Civil Engineers, 32: 335-340

Ootani, M., K. Okamura and I. Yakuwa 1988 Field and numerical studies on the wind-induced internal waves in a reservoir (in Japanese). Annual Journal of Hydraulic Engineering, JSCE, 32: 317-322

Sato, N. 2000 Internal seiche of density interface corresponding to wind stress in a closed water body (in Japanese). Master's thesis of Kyushu university 